\title{
VARIANT ANATOMY OF THE TESTICULAR ARTERY AMONG BLACK KENYANS
}

\author{
Nelson Mpekethu, Peter Gichangi, Beda Olabu, Paul Odula, Jeremiah Munguti, Musa Misiani, Julius A. Ogeng'o
}

Correspondence to Prof Julius Ogeng'o, Department of Human Anatomy University of Nairobi, P.O BOX 30197 - 00100. Email: jogengo@uonbi.ac.ke

\begin{abstract}
Variant anatomy of the testicular artery is important for safe surgery in the retroperioneal area, and accurate diagnosis of testicular and renal disease. The pattern of origin, number, course and branching display ethnic and geographical variations. Data from black African populations and especially Eastern Africa is scarce. The objective of this study was, therefore, to describe the topography of the intraabdominal part of testicular artery in a sample of the Kenyan population. This was a descriptive crosssectional study on one hundred (100) testicular arteries at the Department of Human Anatomy, University of Nairobi. The samples were obtained from autopsy cases and cadaveric specimens. Standard midline abdominal incisions were made, flaps of the anterior abdominal wall reflected and the intestines, mesentery and pariental peritoneum retracted systematically to expose the testicular arteries. Their site and level of origin, number, course and branching were examined. Macrographs of representative variations were taken using a high resolution digital camera. The results were analysed using SPSS version 21 , and are presented using macrographs and frequency tables. Thirty three $(33 \%)$ of the arteries displayed a variant anatomy, with regard to their site of origin ( $8 \%)$, number $(4 \%)$, course $(14 \%)$ and branching pattern (7\%). Among the 14 cases of aberrant course, five $(5 \%)$ arched over the left renal vein, eight (8\%) were retrocaval and one (1\%) had a retroureteric course. Seven $(7 \%)$ bifurcated within the abdomen. The level of origin along the aorta varied from 1 centimetre above the renal arteries to 5.5 centimetres below them while the vertebral level of origin ranged from T12 to L4. This shows that the testicular artery among Kenyans displays a high prevalence of variant anatomy characterized by origin from the accessory renal artery, high level of aortic origin, duplication, retrocaval course and intraabdominal; division. Preopertaive evaluation of renal and gonadal vasculature is recommended to minimize misdiagnosis and inadvertent injury retroperitoneal surgery.
\end{abstract}

\section{INTRODUCTION}

Variant anatomy of the testicular arteries (TA) has been described with respect to site of origin, number, course and branching (Paraskevas et al., 2014; Kotian et al., 2016; Kayalvizhi et al., 2017). These parameters are important for several reasons: first their potential to undermine blood supply to the testis and cause atrophy; secondly, their involvement in testicular and renal diseases like varicocele, hydronephrosis, nephroptosis, renovascular hypertension, testicular atrophy (Mamatha et al., 2015; Chaudhary, 2015), thirdly, they predispose to inadvertent injury during surgery and interventional radiology in the retroperiotoneal area (Nallikuzhy et al., 2017; Shetty and Nayak, 2017); fourthly, they complicate surgical planning, for example renal, testicular and splenic surgery (Bandopadhyay and Saha, 2009; Kayalvizhi et al., 2017); fifthly, the aberrant arteries may serve as a source of collateral blood supply to the kidney through capsular arteries during renal artery stenosis or tumors (Gupta et al., 2010), sixthly, the variations be associated with developmental and vascular anomalies of urogenital system (Gupta et al., 2010) and finally, when unrecognized, the 
may lead to fatal errors during diagnosis and surgical operations (Nallikuzhy et al., 2017). In Sub - Saharan Africa, including Kenya, increase in demand for renal transplant surgery (Muller, 2016; Muturi et al., 2017), and a substantial number of surgical testicular pathology cases (Mbibu et al., 2002) necessitate knowledge of the variant anatomy of these vessels. These variations show population differences (Anjamrooz et al., 2013). Literature from black
African populations is, however, scarce and confined to Southern Africa (Asala et al., 2001; Mazengeya, 2016). Data, from Eastern Africa is only in form of case reports (Misiani et al., 2012, 2014; Kayalvizhi et al., 2017). This study, therefore aimed to provide a wider profile of variations of the testicular arteries in the Kenyan population.

\section{MATERIALS AND METHODS}

This was a descriptive cross - sectional study on one hundred (100) TAs at Department of Human Anatomy, University of Nairobi. The cases comprised autopsy and cadaveric specimens on adult black Kenyans of age range 25 - 94 years. Ethical approval was obtained from the Kenyatta National Hospital, University of Nairobi Ethics and Research Committee, and permission granted by the Chairman of Department.

A standard midline abdominal incision was made and flaps of the anterior abdominal wall together with the intestines were reflected to access the posterior abdominal wall. The parietal peritoneum was then incised to expose the entire length of the intra-abdominal part of each testicular artery. Four parameters were studied, origin with regard to site and vertebral level, distance from renal artery; course in relation to renal vein, inferior vena cava and ureter, number and branching. The distance between the origin of each testicular artery and the origin of the ipsilateral renal artery was measured using a tape measure with an accuracy of $0.1 \mathrm{~cm}$. In order to determine the vertebral level of origin, the L5 vertebra was identified as immediately superior to the sacral promontory. The vertebrae were thereafter counted superiorly to determine the one that corresponded to the origin of the testicular arteries from the aorta. The number of testicular arteries on each side, their course and branching pattern - whether bifurcating or entering the deep inguinal ring as a single trunk was noted.

Morphometric data was analysed using the statistical package for social sciences (SPSS) software (version 21.0 Chicago, Illinois). Normal probability plots were used to determine the distribution of data and upon confirmation of normality, a paired t-test was used to determine the difference in means of the angles of origin on either side. Tables and photomicrographs were used for data presentation.

\section{RESULTS}

Thirty-three (33\%) of the testicular arteries displayed variations. These variations involved site and level of origin, number, course and branching

Out of the one hundred TAs studied, 92\% originated from the aorta (Fig 1A), while 8 originated from accessory renal artery (Fig 1B), all on the right side. The level of origin of the testicular arteries from the aorta varied greatly with respect to the superior mesenteric artery, renal arteries and inferior mesenteric artery. Two arteries arose from the aorta at the same level as the main renal artery and accessory renal artery (Fig 1C). In another case, the TA arose from the aorta just above the inferior mesenteric artery (IMA) (Fig 1D); while in 16 cases, TA arose above the renal artery, at the level of the superior mesenteric artery (SMA) (Fig 1E). In terms of vertebral level, the most frequent vertebral level of origin was L2 (59\%) followed by L3 $(21 \%)$ and L1 (16\%). The highest level of origin noted was $2.0 \mathrm{~cm}$ above the renal arteries at T12 while the lowest was $5.5 \mathrm{~cm}$ below them at L4 [Table 1]. 
Table 1: Vertebral level of origin and the distance from the renal arteries

\begin{tabular}{|l|l|l|l|l|}
\hline & Origin & Right & Left & Percentage \\
\hline Veterbral Level & T12 & 1 & 1 & $2 \%$ \\
\hline & L1 & 7 & 9 & $16 \%$ \\
\hline & L2 & 32 & 27 & $59 \%$ \\
\hline & L3 & 8 & 13 & $21 \%$ \\
\hline & L4 & 1 & 1 & $2 \%$ \\
\hline $\begin{array}{l}\text { Distance from } \\
\text { renal arteries }\end{array}$ & $2.36 \pm 1.53 \mathrm{~cm}$ & $2.46 \pm 1.46 \mathrm{~cm}$ \\
\hline
\end{tabular}
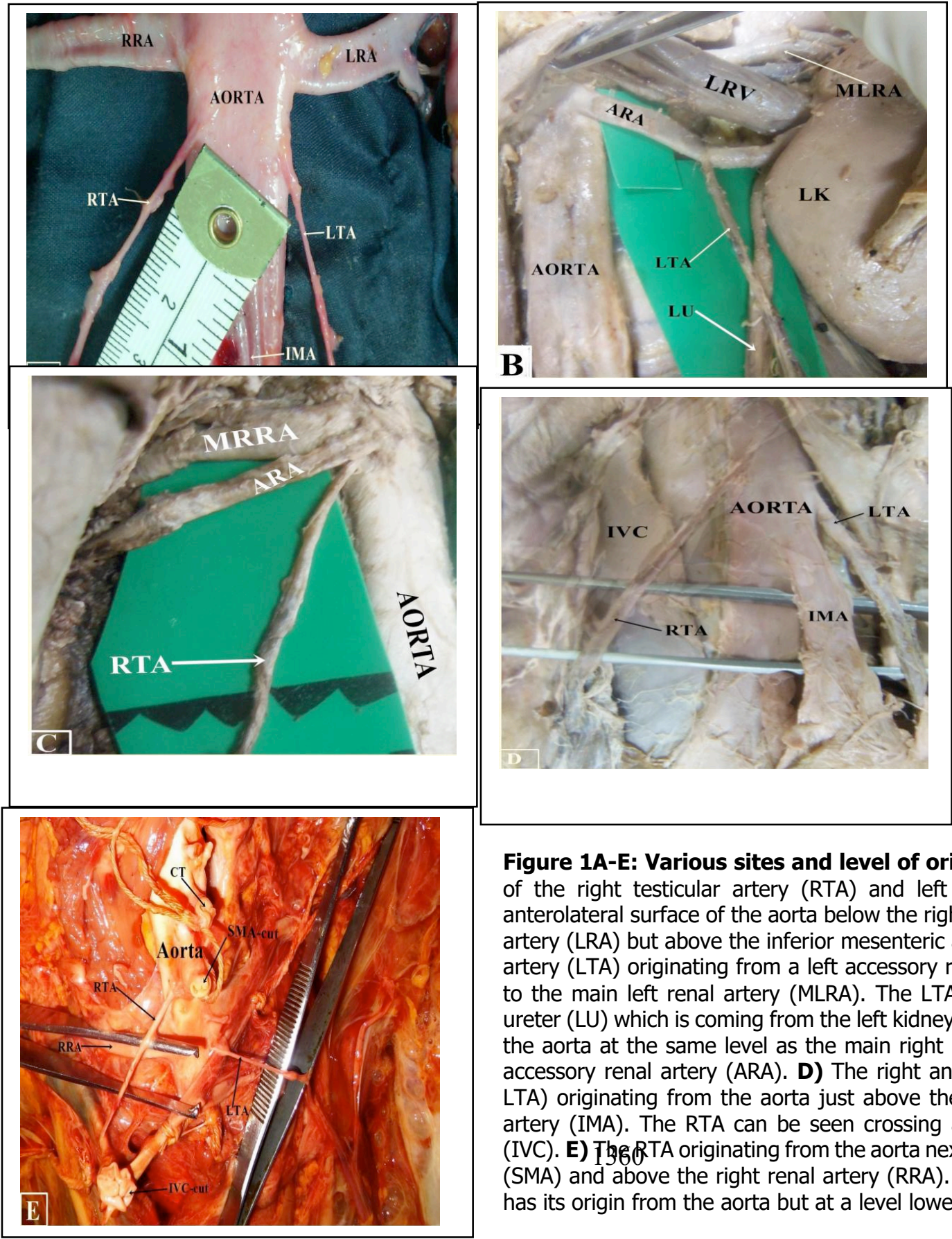

Figure 1A-E: Various sites and level of origin of TAs. A) The normal origin of the right testicular artery (RTA) and left testicular artery (LTA) from the anterolateral surface of the aorta below the right renal artery (RRA) and left renal artery (LRA) but above the inferior mesenteric artery (IMA). B) The left testicular artery (LTA) originating from a left accessory renal artery (ARA) which is inferior to the main left renal artery (MLRA). The LTA then crosses anterior to the left ureter (LU) which is coming from the left kidney (LK). C) The RTA originating from the aorta at the same level as the main right renal artery (MRRA) and the right accessory renal artery (ARA). D) The right and left testicular arteries (RTA and LTA) originating from the aorta just above the origin of the inferior mesenteric artery (IMA). The RTA can be seen crossing anterior to the inferior vena cava (IVC). E) T3\& ( 8 TA originating from the aorta next to the superior mesenteric artery (SMA) and above the right renal artery (RRA). The left testicular artery LTA also has its origin from the aorta but at a level lower than the RTA. 
There were four cases (4\%) of duplicated testicular arteries (Fig 2A). Three of these were on the left while one was on the right. A total of seven (7) TAs bifurcated within the abdomen (Fig 2B) before entering the internal inguinal ring while the rest (93) continued into the internal inguinal ring as single trunks.
There were 14 cases of aberrant course. Five left testicular arteries arched over the left renal vein (Fig 3A), eight (8) followed a retrocaval course (Fig 3B) and one right TA followed a retroureteric course (Fig 3C).
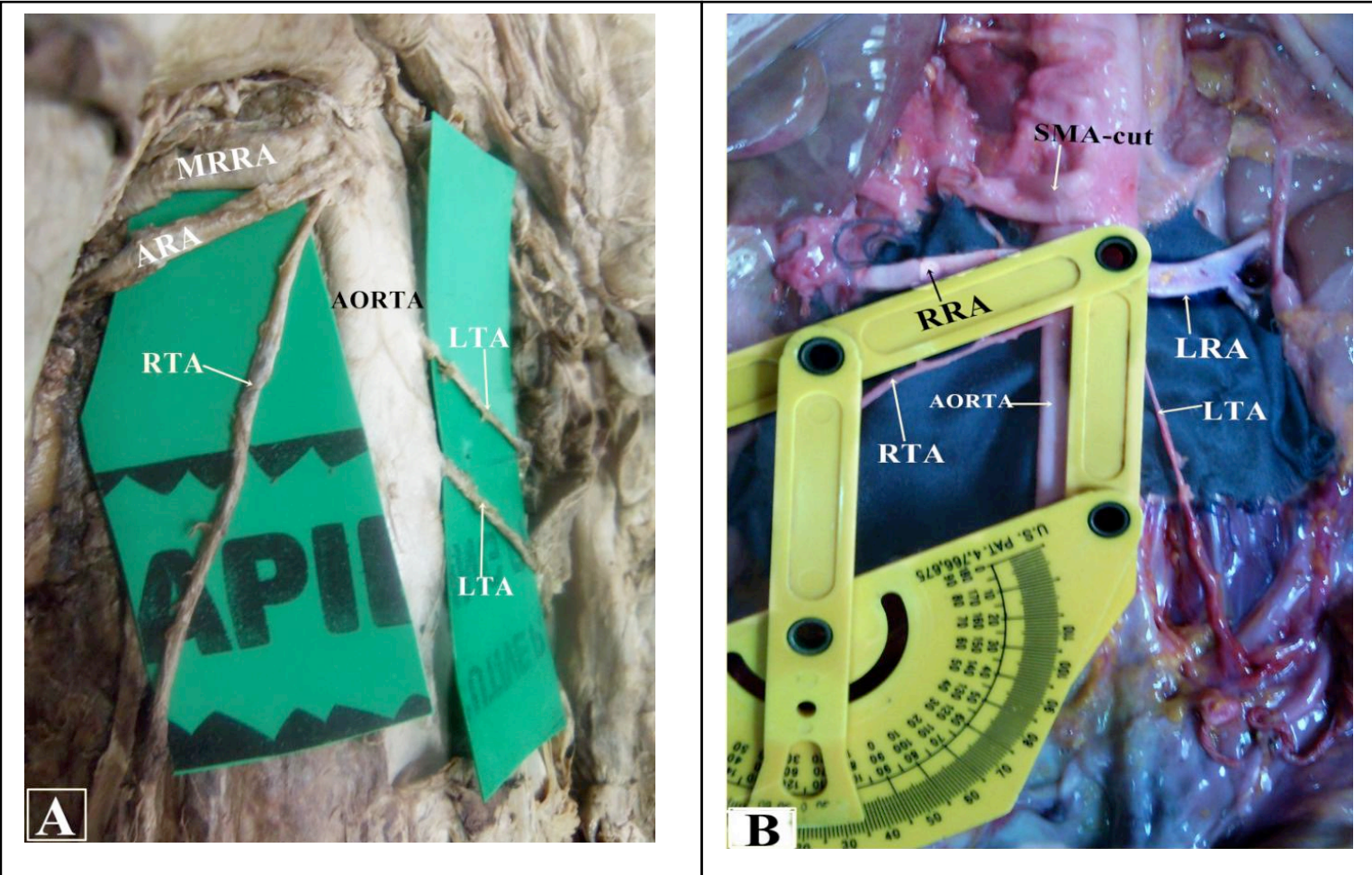

Figure 2A \& B: Variation in the number and branching. Duplicated left testicular artery (LTA). Both of them arise from the aorta but at a lower level than the right testicular artery (RTA). The latter originates from the same level as the right accessory renal artery (ARA) and the main right renal artery (MRRA). The left testicular artery (LTA) originating from the aorta inferior to the cut left renal artery (LRA) and the right renal artery. The LTA can be seen bifurcating just before it crosses anterior to left ureter (LU).

\section{Table 3: Aberrant course testicular artery}

\begin{tabular}{|l|l|l|l|}
\hline Variation & Right & Left & Total \\
\hline Arching over renal vein & 0 & 5 & 5 \\
\hline Retrocaval course & 8 & 0 & 8 \\
\hline Retroureter course & 1 & 0 & 1 \\
\hline Total & 9 & 5 & 14 \\
\hline
\end{tabular}




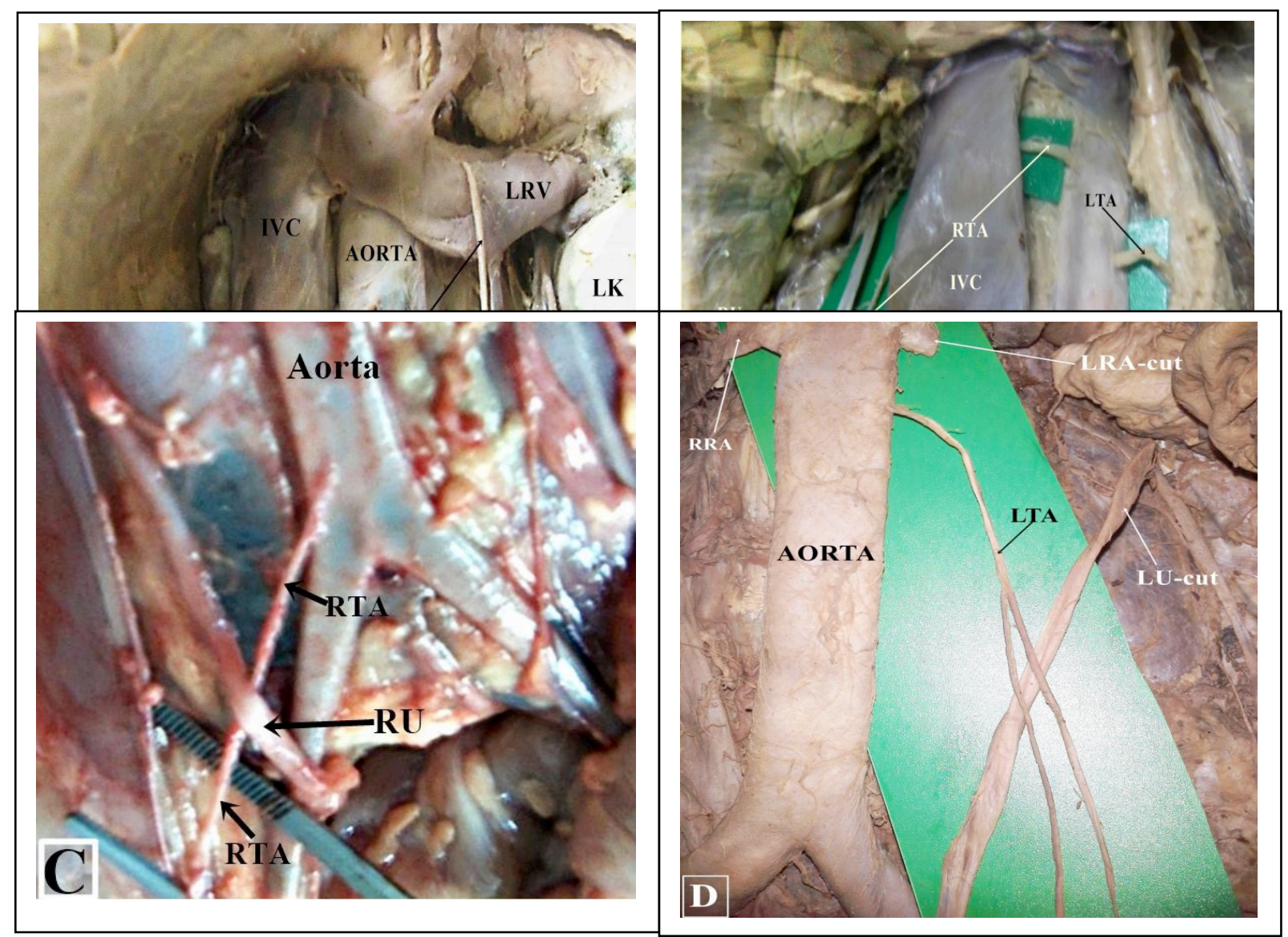

Figure 3A-D: Variation in the course of the intra-abdominal part of testicular arteries. A) The left testicular artery (LTA) arching over the left renal vein (LRV). The right testicular artery originates from the aorta above the inferior mesenteric artery (IMA) and courses anterior to the inferior vena cava (IVC). B) The right testicular artery (RTA) and left testicular artery (LTA) originates from the aorta superior to the inferior mesenteric artery (IMA). The RTA then follows a retrocaval course and crosses anterior to the right ureter (RU). The RTA and the right testicular vein (RTV) then course together inferiorly. C) The right testicular artery (RTA) originating just above the aortic bifurcation. The RTA then courses posterior to the right ureter (RU).

\section{DISCUSSION}

Variant testicular arteries occur in $4.7-21 \%$ of cases (Paraskevas et al., 2014; Kayalvizhi et al., 2017). In the current study the intra-abdominal part of testicular artery was variant in about 33\% of cases. This is much higher than the incidence cited in prevailing literature. Only one study reported $48.4 \%$ (Hussein et al., 2014). This reveals that the degree of variability of TA in the Kenyan population is among the highest and calls for higher caution for those operating in this population.

In the present study, $8 \%$ of the renal arteries originated mainly from the middle segment of an accessory renal artery. This prevalence is within the $0.4-31.3 \%$ reported in prevailing literature. It is comparable with $8.8 \%$ among the Turkish, and $7.4 \%$ among Indians, but generally lower than the others (Kayalvizhi et al., 2017) [Table 3]. 
Table 4: Prevalence of origin of the testicular artery from an accessory renal artery

\begin{tabular}{|l|l|l|l|}
\hline Reference & Population & $\mathbf{N}$ & Prevalence \\
\hline Asala et al., 2001 & South African & 300 & $14 \%$ \\
\hline Bergman et al., 1992 & European & 76 & $15 \%$ \\
\hline Cicekcibasi et al., 2002 & Turkish & 180 & $8.8 \%$ \\
\hline Pai et al., 2008 & Indian & 68 & $7.4 \%$ \\
\hline Petru et al., 2007 & Australian & 16 & $31.25 \%$ \\
\hline Present study & Kenyan & $\mathbf{1 0 0}$ & $\mathbf{8 \%}$ \\
\hline
\end{tabular}

Testicular arteries originating from ARA are vulnerable to injury during percutaneous treatment of syndrome of pelvic -ureteral junction (Mamatha et al., 2015).

These population differences depicted in Table 4 should be borne in mind to ensure accurate interpretation of abdominal angiographs and successful retroperitoneal procedures (Ruder et al., 2012; Chevallier et al., 2013).

A notable observation in the current study is that in no case, did the artery arise from the other sources such as main renal artery, lumbar, common iliac, internal iliac, epigastric or subscostal (Mamatha et al., 2015; Kayalvizhi et al., 2017). This implies that in cases of accessory renal artery, which is prevalent in the Kenyan population (Ogeng'o et al., 2010; Sungura et al., 2018) due care should be taken to minimize inadvertent injury to the aberrant testicular artery.

Testicular arteries usually arise from the aorta at the level of L2, below the renal arteries (Mamatha et al., 2015). In the current study, over $30 \%$ of cases fell outside this range.

The level of origin of the testicular arteries along the aorta, in the current study, was found to be highly variable. The highest origin observed was $2.0 \mathrm{~cm}$ above the renal arteries at the $\mathrm{T} 12$ vertebral level where the RTA originated together with the superior mesenteric artery. This finding is comparable to other studies in which the TA has been reported to originate from the aorta, $1.1 \mathrm{~cm}$ to $2.2 \mathrm{~cm}$ above the renal arteries (Paraskevas et al., 2011; Royana et al.,
2011; Li et al., 2012; Lakshami et al., 2013). The lowest origin was below the inferior mesenteric artery, $5.5 \mathrm{~cm}$ below the renal arteries at $L 4$. Previous researchers have observed much lower origins, including from the lumbar, common iliac, internal iliac and the inferior epigastric arteries (Onderoğlu et al., 1993; Ozan et al., 1995; Mirapeix et al., 1996; Tanyeli et al., 2006; Petru et al., 2007).

Variations in the levels of origin of the testicular arteries have an embryological basis (Shoja et al., 2007; Li et al., 2012). Testicular arteries develop as lateral persistent splanchnic branches of the aorta that enter the mesonephros in fetal life (Standring 2008). These mesonephric arteries supply the developing gonads, the suprarenal gland, the diaphragm and the kidney (Bandopadhyay and Saha, 2009). Those supplying the gonads develop superior to the renal arteries since the developing gonads are cranial to the developing kidneys. With the gradual descent of the gonads, new lower branches arise and the higher branches degenerate. The persistence of a cranial lateral mesonephric artery results in a high origin of the testicular artery, while the persistence of an excessively caudal branch leads to a low origin of the testicular artery (Salve and Ratanprabha, 2011). The present range of variations in the level of origin can be attributed to the persistence of cranial and caudal mesonephric arteries.

These variations in the level and site of origin are clinically relevant in the advent of laparoscopic procedures including pyeloplasty and 
endopyelotomy (Ost et al., 2005). In such procedures, the anomalous testicular arteries can be erroneously ligated or injured leading to testicular infarction.

Testicular arteries may be 2, 3 or upto 7. Such multiple arteries are commonly documented as case reports (Esparagoza et al., 2017; Filipovic et al., 2012; Kotian et al., 2016). The reported frequency of double testicular arteries ranges from 1- 25\% (Paraskevas et al., 2014; Pery et al., 2007). The present study reports $4 \%$ prevalence of duplications three on the left while one was on the right. Duplication of testicular artery may be associated with other vascular variations, may cause confusion in interpretation of angiograms and be vulnerable to injury during surgery (Paraskevas et al., 2014). Embryologically, duplication of the testicular artery has been postulated to result from persistence of more than one mesonephric artery (Keith et al., 2011) with regard to intrabdominal branching, the present study revealed prevalence of $7 \%$. This comparable to $5 \%$ reported in an Indian population (Kotian et al., 2016). This branching pattern has previously been shown to occur with other variations of the testicular artery and the renal vessels (Anjamrooz et al., 2012). The significance of this intrabdominal branching is similar to that of duplication (Paraskevas et al., 2014). Accordingly, surgeons and radiologists should be aware of this variation in order to minimize their inadvertent and radiographic misdiagnosis.

Fourteen (14\%) of the arteries, in the present study, had aberrant course, consistent with upto 20\% cases in literature (Lippert and Pabst, 1985; $\mathrm{Li}, 2015)$. These variations are also commonly documented only as case reports (Onderoğlu et al., 1993; Ozdemir et al., 2004; Royana et al., 2011; Li, 2015). In Eight (8\%) of cases, the artery was retrocaval. Retrocaval testicular arteries are important because of their co existence with variations involving the testicular veins and the renal vessels (Anjamrooz et al., 2013; Aithal et al., 2014). When present, this retrocaval course increases risk of inadvertent injury of these anomalous vessels during procedures such as in renal transplants (Ogeng'o et al., 2010). The high prevalence of retrocaval TA calls for extra care during operations in the retroperitoneal area.

Developmentally both testicular arteries represent persistent lateral splanchnic aortic branches that enter the mesonephros and cross ventral to the supracardinal but dorsal to the subcardinal vein (Hamilton and Mossman, 1973). During normal development the lateral splanchnic artery that persists as the right testicular artery and passes caudal to the suprasubcardinal anastomosis which forms part of the inferior vena cava. When it passes cranial to this, the right testicular artery may lie behind the inferior vena cava (Lelli et al., 2014; Aithal et al., 2014; Li, 2015).

The prevalence of the left testicular artery arching over the left renal vein, the so called artery of Luschka, was $5 \%$. This is within the range of $1.7-20.3 \%$ reported in various populations (Naito et al., 2006, 2011; Kayalvizhi et al., 2017). This variation is important for several reasons - the artery may be compressed causing testicular degeneration, it may form a component of the renal pedicle in which case it is more vulnerable to injury during renal surgery (Singh et al., 2011), may precipitate left renal vein hypertension and left varicocele (Naito et al., 2006, 2011; Ranade et al., 2008), predisposes the testicular arteries to iatrogenic injury during surgical procedures in the retroperitoneal region (Klemm et al., 2005), and can cause the compression of the renal vein (Yang et al., 2007).

The course of the testicular artery posterior to the ureter is a rare anomaly that has been observed in conjunction with a duplicated ureter (Fernbach et al., 1997). In the present study, one testicular artery was retroureteric. This course may predispose the testicular artery to compression by the ureter. Consequently, there is need for extra caution when carrying out procedures in the posterior abdominal wall (Ost et al., 2005; Rassweiler et al., 2007). 
In conclusion, the testicular artery among black Kenyans displays a high prevalence of variant anatomy characterized by high level of aortic origin, duplication, origin from accessory renal artery, retrocaval course and intraabdominal division. Preoperative evaluation of renal and gonadal vasculature is recommended to minimize in advertent injury during retroperitoneal surgery.

ACKNOWLEDGEMENTS: We are grateful to technical staff of the department of Human anatomy and to Antonina Odock - Opiko for typing the manuscript.

CONFLICT OF INTEREST: There was no conflict of interest in this study.

\section{REFERENCES}

1. Aithal AP, Kumar N, Ravindra SS, Patil J, Shetty SD, Abhinitha P. 2014. Retrocaval testicular artery associated with vascular variations of right kidney and its surgical importance. Sch J Med Case Rep. 2: $316-318$.

2. Anjamrooz H, Taghav M, Abedinzadeh M, Yazdi M, Azari H. 2013. Coexistence of multiple arterial variations in the genitourinary system. Ital J Anat Embryol. 118: 128-135.

3. Asala S, Chaudhary C, Masumbuko-Kahamba N, Bidmos M. 2001. Anatomical variations in the human testicular blood vessels. Ann Anat. 183: 545-549.

4. Bandopadhyay M, Saha A. 2009. Three rare variations in the course of the 60 nadal artery. Int J Morphol. 27: $655-659$.

5. Bergman A, Cassell D, Sahinoglu K, Heidger M. 1992. Human doubled renal and testicular arteries. Ann Anat. 174: 313-315.

6. Chaudhary S. 2015. A cadaveric study of the testicular artery. Ind J Fund Appld Life Sci. $48-50$.

7. Ciçekcibaşi E, Salbacak A, Seker M, Ziylan T, Büyükmumcu M, Uysal I. 2002. The origin of gonadal arteries in human fetuses: anatomical variations. Ann Anat Anat Anz Off Organ Anat Ges. 184: 275-279.

8. Esparagoza RE, Chacon CS, Acosta $A E$, Chacin JE. An unusual case of duplication of the right resticular artery. Int J anat Var, 2017; 10: 8 - 9.

9. Fernbach K, Feinstein A, Spencer K, Lindstrom A. 1997. Ureteral duplication and its complications. Radiogr. 17: 109-127.

10. Filipovic B, Stijak L, Filipovic B. 2012. An unusual origin of the double testicular artery in a male cadaver: a case report. J med Case Rep. 6: 267.

11. Hamilton W, Mossman M. 1973. Human embryology, prenatal development of form and function, 4th ed. Williams \& Wilkins Co, Baltimore.

12. Hussein M, Deep V, Gupta P, Sharma AK, Yadav AK. 2014. Variable origin of testicular artery from renal artery and its clinical significance in North Indian population. Sch J App Med Sci. 4: 407 410.

13. Kayalvizhi I, Narayan RK, Kumar P. 2017.Anatomical variations in testicular artery: a review. Folia Morphol (warz), 2017; 76: 541 - 550.

14. Keith L, Persaud T, Mark G. 2011. The Developing Human: Clinically Oriented Embryology, 9th ed. Elsevier Churchill Livingstone.

15. Kim Y, Joh H, Choi Y, Do S, Shin W, Kim I. 2006. Transposition of the left renal vein in nutcracker syndrome. Eur. J. Vasc. Endovasc. Surg. 31, 80-82.

16. Klemm P, Fröber R, Köhler C, Schneider A. 2005. Vascular anomalies in the paraaortic region diagnosed by laparoscopy in patients with gynaecologic malignancies. Gynecol. Oncol. 96, 278282. 
17. Kotian SR, Pandey AK, Padmashalli S, Jaison J, Kalthur SG. A cadaveric study of the testicular artery and its clinical significance. J Vasc Bras, 2016; 15: 280 - 286.

18. Lakshami B, Singh A, Shetty S. 2013. High origin of left testicular artery associated with accessory renal artery and renal cyst; a cadaveric observation. Int. J. Res. Med. Sci. 1, 308.

19. Lelli, F., Maurelli, V., Maranillo, E., Valderrama-Canales., 2014. Arched and retrocaval testicular arteries: A case report. Eur. J. Anat. 11, 119-122.

20. Li J, Ren ZF, Sun T. Bilateral high origins of testicular arteries: a rare variant. Rom J Morphol Embryol, 2012; 53: $427-429$.

21. Li J. A retrocaval right testicular artery with an arching left testicular artery. Eur J Anat, 2015; 19: $85-86$.

22. Mamatha $H$, D'Souza AS, Vinodhini $P$, Biswabina $R$ et al. A cadaveric study about the anomalous origin of testicular arteries. Ind J Surg, 2015; 77: $111-116$.

23. Mazengeya P. Multiple variations of the renal and testicular vessels: possible embryological basis and clinical importance. Surg Rad Anat, 2016; 38: 729 - 733.

24. Mbibu NH, Nwofor AME, Khalid L. Spectrum of urologic disease in the West African sub region. Ann Afr Med, 2002; 1: $44-52$.

25. Mirapeix, M., Sañudo, R., Ferreira, B., Domenech-Mateu, M., 1996. A retrocaval right testicular artery passing through a hiatus in a bifid right renal vein. J. Anat. 189, 689-690.

26. Misiani MK, Loyal PK, Ogeng'o JA, Saidi HS. High origin of the right testicular artery coursing through a hiatus in the inferior vena cava. Anat J Afr, 2014; 3: $372-375$.

27. Misiani MK, Ongeti K, Ogeng'o J. Anomalous origin of the left testicular artery from an additional renal aartery. Anat JAfr, 2012; $1: 14-16$.

28. Mohandas GV, Ismail BM, Vijayalakshmi K, Sunitha V, Devi B, Rojarani CH, Durgesh V. Source of origin of testicular artery: A cadaveric study. J Evid Base Med Health Care, 2014; 1: 37 - 40.

29. Muller E. Transplantaion in Africa - an overview. Clinical Nephrology, 2016; 86: s 90 - s 95.

30. Muturi A, Kotecha V, Kanyi S. A retrospective study to assess the evaluaton of living related kidney donors and their outcomes following nephrectomy at Kenyatta National Hospital. BMC Nephrology, 2017; 18: 171.

31. Naito, M., Terayama, H., Nakamura, Y., Hayashi, S., Miyaki, T., Itoh, M., 2006. Left testicular artery arching over the ipsilateral renal vein. Asian J. Androl. 8, 107-110.

32. Onderoğlu, S., Yüksel, M., Arik, Z., 1993. Unusual branching and course of the testicular artery. Ann. Anat. 175, 541-544.

33. Ost, C., Kaye, D., Guttman, J., Lee, R., Smith, D., 2005. Laparoscopic pyeloplasty versus antegrade endopyelotomy: Comparison in 100 patients and a new algorithm for the minimally invasive treatment of ureteropelvic junction obstruction. Urology 66, 47-51.

34. Ozan, H., Gümüşalan, Y., Onderoğlu, S., Simşek, C., 1995. High origin of gonadal arteries associated with other variations. Ann. Anat. 177, 156-160.

35. Ozdemir, B., Celik, H., Aldur, M., 2004. Altered course of the right testicular artery. Clin. Anat. 17, 67-69.

36. Pai, M., Vadgaonkar, R., Rai, R., Nayak, R., Jiji, J., Ranade, A., Prabhu, V., Madhyastha, S., 2008. A cadaveric study of the testicular artery in the South Indian population. Singapore Med. J. 49, 551-555.

37. Paraskevas GK, Natsis K, Nitsa Z, Papaziogas B, Kitsoulis P. Bilateral double testicular arteries: a case report and review of literature. Potential embryological and surgical considerations. Folia Morphol, 2014; 73: 383 - 387.

38. Petru, B., Elena, S., Dan, I., Constantin, D., 2007. The morphology and the surgical importance of the gonadal arteries originating from the renal artery. Surg. Radiol. Anat. 29, 367-371. 
39. Ranade A, Rai R, Nayak S. Arched left gonadal artery over the left renal vein associated with left renal artery. Surg Med J, 2008; 48: e332 - 334.

40. Rassweiler, J., Subotic, S., Feist-Schwenk, M., Sugiono, M., Schulze, M., Teber, D., Frede, T., 2007. Minimally Invasive Treatment of Ureteropelvic Junction Obstruction: Long-Term Experience With an Algorithm for Laser Endopyelotomy and Laparoscopic Retroperitoneal Pyeloplasty. J. Urol. $177,1000-1005$.

41. Ravery, V., Cussenot, O., Desgrandchamps, F., Teillac, P., Martin-Bouyer, Y., Lassau, P., Le Duc, A., 1993. Variations in arterial blood supply and the risk of hemorrhage during percutaneous treatment of lesions of the pelviureteral junction obstruction: report of a case of testicular artery arising from an inferior polar renal artery. Surg. Radiol. Anat. 15, 355-359.

42. Royana, S., Jaiswal, A., Shamal, N., Singh, P., 2011. Variation in the Origin of the Testicular Arteries and Drainage of the Right Testicular Vein. Int. J. Morphol. 29, 614-616.

43. Ruder, D., Hatch, M., Ebert, C., Flach, M., Ross, S., Ampanozi, G., Thali, J., 2012. Whole body postmortem magnetic resonance angiography. J. Forensic Sci. 57, 778-782.

44. Rusu, C., 2006. Human bilateral doubled renal and testicular arteries with a left testicular arterial arch around the left renal vein. Romanian J. Morphol. Embryol. 47, 197-200.

45. Salve, M., Ratanprabha, C., 2011. Multiple variations of branches of abdominal aorta. Kathmandu Univ. Med. J. 9, 72-76.

46. Shetty P, Nayak SB. A detailed study of multiple vascular variations in the upper part of abdomen. J Cardiovasc Echography, 2017; 27: 7 - 9.

47. Shoja, M., Tubbs, S., Shakeri, B., Oakes, J., 2007. Origins of the gonadal artery: embryologic implications. Clin. Anat. 20, 428-432.

48. Singh R, Jaiswal A, Shamal SN, Singh SP. Variation in the origin of the testicular arteries and drainage of the right testicular vein. Int J Morphol, 2011; 29: 614-616.

49. Skandalakis, L., 2004. Skandalakis Surgical Anatomy: The Embryologic and Anatomic Basis of Modern Surgery 2 Vol. set, 1 edition. ed. P.M.P, Athens; London.

50. Standring, S., 2008. Gray's Anatomy The Anatomical Basis of Clinical Practice, 40th ed. Elsevier Churchill Livingstone, London.

51. Sungura R, Onyambu C, Mathenge I. The CT angiographic prevalence of renal accessory arteries in Kenya. Int J Current Microbiol Applied Sci, 2018; 7: 2745 - 2754.

52. Tanyeli, E., Uzel, M., Soyluoğlu, I., 2006. Complex renal vascular variation: a case report. Ann. Anat. $188,455-458$.

53. Thompson, E., Thompson, T., Munera, F., Cohn, M., MacLean, A., Cameron, J., Rivas, L., Bajayo, D., 2006. Novel computed tomography scan scoring system predicts the need for intervention after splenic injury. J. Trauma 60, 1083-1086. 